\title{
Giardia lamblia Antigen Measurement
}

National Cancer Institute

\section{Source}

National Cancer Institute. Giardia lamblia Antigen Measurement. NCI Thesaurus. Code C154822.

The determination of the Giardia lamblia antigen present in a sample. 